Article

\title{
A New Generation of Sustainability Governance: Potentials for 2030 Agenda Implementation in Swiss Cantons
}

\author{
Basil Bornemann * and Marius Christen \\ Sustainability Research Group, Department of Social Sciences, University of Basel, 4051 Basel, Switzerland; \\ E-Mails: basil.bornemann@unibas.ch (B.B.), marius.christen@unibas.ch (M.C.) \\ * Corresponding author
}

Submitted: 23 September 2020 | Accepted: 1 February 2021 | Published: 26 February 2021

\begin{abstract}
Governments and administrations at all levels play a central role in shaping sustainable development. Over the past 30 years, many have developed differentiated sustainability governance arrangements (SGAs) to incorporate sustainability into their governing practice. The 2030 Agenda for Sustainable Development, which the UN adopted in 2015, brings with it some significant conceptual shifts in sustainability thinking that, in turn, entail new governance requirements. Starting from practical calls for improved understanding of the requirements and conditions of 2030 Agenda implementation 'on the ground,' this article examines existing SGAs' potential to deal with the generational shift that the 2030 Agenda implies. To this end, four ideal-typical SGAs representing an early generation of sustainability governance at the subnational level in Switzerland are related to five specific governance requirements emerging from the 2030 Agenda. The analysis highlights different possibilities and limitations of the four SGAs to meet 2030 Agenda requirements and points to the need for context-specific reforms of first-generation sustainability governance in the wake of the new Agenda.
\end{abstract}

\section{Keywords}

2030 agenda; governance transformation; government; subnational level; sustainability governance; Sustainable Development Goals; Switzerland

\section{Issue}

This article is part of the issue "The 2030 Agenda for Sustainable Development: Transformative Change through Sustainable Development Goals?" edited by Thomas Hickmann (University of Utrecht, The Netherlands), Markus Lederer (Technical University of Darmstadt, Germany), Jens Marquardt (Technical University of Darmstadt, Germany), Sandra Schwindenhammer (Justus Liebig University Giessen, Germany) and Sabine Weiland (Catholic University of Lille, France).

(C) 2021 by the authors; licensee Cogitatio (Lisbon, Portugal). This article is licensed under a Creative Commons Attribution 4.0 International License (CC BY).

\section{Introduction}

Since the emergence and spread of the idea of sustainable development, governments and public administrations have been playing a central role in its implementation. In addition to pursuing specific sustainability goals through concrete sectoral policy action (e.g., energy and climate policies targeting greenhouse gas emissions), governments have become engaged in sustainability-oriented meta-governance (Meuleman, 2019; Meuleman \& Niestroy, 2015). This involves making sustainability-including its specific characteristics, such as a long-term perspective or the integrated consideration of social, economic, and environmental dimensions-an orientation that permeates and guides all governmental and administrative actions. To this end, governments have developed manifold institutions and practices over the past 30 years, including administrative units responsible for sustainability, overarching sustainability visions and strategies, and sustainability impact assessments (Lafferty \& Meadowcroft, 2000; Steurer, 2010). In concrete contexts, different institutions and practices together form complex sustainability governance arrangements (SGAs; Bornemann, 2014). With their focus on shaping the conditions for policymaking and governance along normative and functional 
sustainability requirements, SGAs perform an internal sustainability-oriented meta-governance function geared toward 'sustainabilizing the government machinery' (Bornemann \& Christen, 2019a, 2019b).

The 2030 Agenda marks a new milestone in the development of sustainability thinking and governance. For the first time in history, the international community has agreed on a global, long-term, comprehensive, and (relatively) tangible Agenda aimed at a systemic transformation of the world toward sustainability (Biermann, Kanie, \& Kim, 2017; Kanie \& Biermann, 2017). The new agenda entails several shifts in the understanding of sustainable development that carry implications for the interpretation and practice of sustainability governance (Bowen et al., 2017; Hajer et al., 2015; Meuleman \& Niestroy, 2015). For example, it concretizes the normative quality of sustainability by defining 17 global Sustainable Development Goals (SDGs) and 169 targets, as well as accentuates the integrative claim of sustainability by emphasizing the systemic linkages of goals as a central element of sustainability (Boas, Biermann, \& Kanie, 2016; Le Blanc, 2015; Nilsson \& Weitz, 2019; Stafford-Smith et al., 2017).

While a wealth of experience already exists at the national level (see, e.g., Allen, Metternicht, \& Wiedmann, 2018; Forestier \& Kim, 2020; Tosun \& Leininger, 2017), implementation of the 2030 Agenda still seems to be in its infancy at the subnational level (cf. Valencia et al., 2019). For example, in Switzerland, the national government plays a pioneering role in implementing the 2030 Agenda, whereas the cantons display only sporadic implementation efforts. Cantonal administrations are merely getting ready to begin considering the new Agenda in their actions. From several background conversations and interviews with administrative practitioners working in cantonal sustainability units, we know that they face the challenge of determining whether and to what extent they can rely on existing SGAs to implement the 2030 Agenda and how they should further develop these arrangements to prepare them for the new Agenda's specific requirements.

Motivated by this practical concern, this article examines present-generation SGAs' potential for implementing the 2030 Agenda by asking: To what extent are existing SGAs prepared to meet the new governance requirements of the 2030 Agenda? We address this question through an exemplary analysis of four idealtypical SGAs that we identified in a previous study on sustainability governance practices in cantonal administrations in Switzerland (Bornemann \& Christen, 2019a, 2019b). While these types of SGAs (problem-oriented, management-oriented, strategy-oriented, and networkoriented) are characteristic of the pre-2030 Agenda phase in Switzerland, their general nature makes them very likely applicable beyond this context. By examining these four ideal-typical governance arrangements in terms of their possibilities and limitations for considering newly emerging governance requirements from the 2030 Agenda, our analysis sheds light on how pre-established governance contexts could shape its implementation. Specifically, it contributes to a richer "understanding of the diverse contexts and ways in which governments will have to navigate and address the inevitable choices and conflicts, synergies and trade-offs" associated with the Agenda's implementation (Newell et al., 2019, p. 1).

Considering its underlying practical concern, our study is not to be seen as a classical, theoretically based, empirical analysis that takes a backward-looking perspective to describe and explain what is the case and why. In the spirit of a forward-oriented approach to transformative sustainability research (see Jahn, Bergmann, \& Keil, 2012), it instead aims to examine to what extent existing (governance) systems can enable or block the implementation of certain governance requirements (see, on exploration, Börjeson, Höjer, Dreborg, Ekvall, \& Finnveden, 2006). To this end, our analysis combines empirically generalized system knowledge (i.e., the functioning of four ideal-typical SGAs) with orientation knowledge (i.e., the 2030 Agenda's new governance requirements). This lays a foundation for generating (action-oriented) transformation knowledge on how the 2030 Agenda can be implemented more effectively in diverse governance contexts 'on the ground,' as well as determining which governance transformations will be necessary for this (see Grunwald, 2007).

Following this introduction, we outline the four idealtypical SGAs that we view as characteristic of the early generation of sustainability governance in Swiss cantons (Section 2). We then specify five conceptual shifts that are characteristic of the new generation of 2030 Agenda sustainability thinking, giving rise to new governance requirements (Section 3). Confronting these emerging requirements with the four ideal-typical SGAs, we examine the latter's possibilities and limitations to meet the 2030 Agenda's governance requirements (Section 4). We conclude with perspectives for future research and practice (Section 5).

\section{An Early Generation of Sustainability Governance: Four Ideal-Typical Governance Arrangements in Swiss Cantons}

Governments have reacted in many ways to the rise of the sustainability agenda. In addition to aligning specific sectoral policies with sustainability goals, we can observe the development of more general sustainability-oriented governance arrangements at various governmental levels (Baker \& Eckerberg, 2008; Bruyninckx, Happaerts, \& Van den Brande, 2012; Lafferty \& Meadowcroft, 2000; Steurer, 2008). These refer to configurations of institutional, procedural, and programmatic elements geared toward the systematic consideration, internalization, and implementation of sustainability concerns in government and administrative actions. In the sense of sustainability-oriented meta-governance (Meuleman, 
2019), they aim at the 'sustainabilization of the government machinery,' i.e., the sustainability-oriented transformation of the conditions and orientations of governmental actions (Bornemann \& Christen, 2019a, $2019 b)$. At the national level, these arrangements typically comprise national sustainability strategies and related institutions and processes, forming a considerable variety of sustainability arrangements (see, e.g., OECD, 2007; Steurer \& Hametner, 2013; Volkery, Swanson, Jacob, Bregha, \& Pintér, 2006). Given that subnational governments are less tied to international obligations, they tend to have even greater leeway in interpreting and implementing sustainability governance on the ground (Baker \& Eckerberg, 2008; Bruyninckx et al., 2012).

Based on a qualitative study that refers to the subnational level in Switzerland, we identified four ideal-typical approaches to anchoring sustainability in government actions, namely problem-oriented, management-oriented, strategy-oriented, and networkoriented SGAs. These four ideal types are characterized by specific configurations of polity-, policy- and politics-related governance conditions and activities, the interaction of which produces characteristic governance rationales, i.e., ways of knowing and doing sustainability governance 'on the ground' (see, for more details, Bornemann \& Christen, 2019a).

\subsection{Problem-Oriented Sustainability Governance Arrangement}

The problem-oriented SGA type is characterized by a distinct focus on concrete sustainability problems and policies. Within such governance arrangements, administrators tend to adopt a pragmatic logic of administrative policymaking (Hansen \& Ejersbo, 2002; Paehlke \& Torgerson, 1990), i.e., they aim to solve problems within given administrative structures and procedures. The unit responsible for sustainability typically is located in a specialized department, usually the environmental department, and, thus, is embedded in the normal bureaucratic decision-making mechanism. Sustainabilityoriented activities are based on a stable legitimation framework comprising executive orders or subordinate laws prescribing sustainability-oriented tasks for the administration. Administrative actors responsible for sustainability view themselves as acting in a rather rigorous and formalized setting without major opportunities to shape their own working conditions. They respond to requests by providing support to other units in the form of problem-oriented expertise or reports (e.g., cantonal sustainability reports), as well as with instructions or instruments (e.g., sustainability assessments). Apart from occasional meetings, they have no direct access to political decision-makers, such as elected politicians or high-level administrators. The dominant practice in administrations belonging to this type of sustainability governance arrangement comprises incremental and selective problem-solving.

\subsection{Management-Oriented Sustainability Governance Arrangement}

The management-oriented approach to sustainability governance in government and public administration is distinguished by goal-oriented steering and monitoring (Christensen \& Lægreid, 2006; Steurer, 2007). Unlike incremental problem-oriented SGAs, this type is geared toward designing a decision architecture that enables the efficient implementation of politically defined sustainability goals. Efficiency is viewed as the central guiding principle of sustainability governance, to be achieved through a management cycle that enables the systematic and rational implementation of goals through continuous monitoring and evaluation. Accordingly, sustainability-oriented administrative bodies are concerned with the development and implementation of sustainability indicators, although these typically relate less to the level of policy outputs and more to aggregate social developments. In addition, sustainability units are concerned with the communication and visualization of these indicators within the administration, the further development of internal processes, and the design and promotion of instruments for the exante sustainability assessment of policies and projects. Sustainability units typically are located somewhere high in the administrative hierarchy, close to the politicaladministrative decision center (i.e., the core executive). Their activities rely on a strong legitimation basis-such as high-level political decisions, laws, or even constitutional norms-interpreted in terms of sustainability. The dominant practice in this SGA type is oriented toward adhering to and optimizing administrative procedures so that they support sustainable decision-making.

\subsection{Strategy-Oriented Sustainability Governance Arrangement}

Similar to the management-oriented approach, the strategy-oriented SGA type is characterized by attempts to improve governance conditions for sustainable development actively and systematically. However, in this approach, sustainability actors also extend their orientation and activities to the politics dimension. They consciously combine (substantive) policy and (powerrelated) politics considerations to promote sustainability in a goal-oriented way (Tils, 2007). More than with the other types, sustainability units in these SGAs participate in the political game, e.g., by addressing different hierarchical levels within the administration and also by influencing the political agenda. Sustainability units can do so because they are positioned at the top of the administrative hierarchy. Although they do not normally have directive authority, they are linked closely to the center of political power, a position they use to engage actively with political and administrative decision-makers, as well as mobilize support for sustainability issues. Therefore, sustainability governance is based not only on legal but 
also on considerable political legitimation. The predominant concern with sustainability governance under the strategic approach is to create, shape, and use political opportunities for sustainability.

\subsection{Network-Oriented Sustainability Governance Arrangement}

The network-oriented SGA type is characterized by its distinct focus on creating collaborative relationships with actors inside and outside the administration (Koppenjan \& Klijn, 2004). Compared with the other types, formal policies and even constitutional goals that provide orientation for sustainability governance play a minor role. Instead, this type is characterized by flexible, timelimited sustainability programs and projects. The formal responsibility for sustainability is located at some distance from the political decision centers. Sustainability units sometimes are even outsourced to external bodies, such as state foundations. They operate on the periphery of the state, but given their (financial and informational) dependencies, in the 'shadow of hierarchy.' Rather than approaching political decision-makers, sustainability units realize their diverse goals and projects by searching for varied collaborators. Because they operate outside of administrative hierarchies, they try to build supportive and flexible networks with administrative and social actors. Sustainability units demonstrate strong concerns about sustainability issues and have a relatively large amount of autonomy in setting their own agendas. They conceive of themselves as independent experts and advisors in sustainability issues who provide support to other administrative units and societal actors. Overall, networking and collaboration with societal and administrative actors to mobilize support for sustainability concerns are the dominant practices under networkoriented sustainability governance.

Overall, the four ideal types illustrate a broad spectrum of ways to pursue sustainability governance in the context of government and administration. Actual real-world SGAs may combine elements of different types into hybrid forms. Although we have derived the four types from sustainability governance in Swiss cantons, we assume that they represent basic rationales that potentially can be found in other contexts as well. We now turn to the question with which specific governance requirements the 2030 Agenda confronts these early-generation SGAs.

\section{A New Generation of Sustainability Thinking: Five Governance Requirements from the 2030 Agenda}

The 2030 Agenda, adopted by the UN General Assembly in 2015, represents an unprecedented milestone in international sustainability politics, which began more than 30 years ago with the Brundtland Report and took shape through a series of global environment and development conferences (Meadowcroft et al., 2019). In its basic normative thrust-the realization of intertemporal and international justice under the conditions of fundamental ecological limits-the 2030 Agenda displays considerable continuity with the sustainability discourse that precedes it. However, it also entails several significant conceptual shifts, i.e., changed interpretations of basic elements of sustainability thinking that together can be interpreted as a new generation of sustainability thinking. Whatever the underlying drivers might be-whether it is the integration of sustainability with the Millennium Development Goals (Boas et al., 2016; Fukuda-Parr, 2016; Langford, 2016), the rise of the Anthropocene as a new ontological framework (Biermann \& Lövbrand, 2019), or the increasing reference to 'transformation' discourse (Brand, 2017) - these shifts in sustainability thinking also involve changed understandings of which governance forms are viewed as appropriate and functional with regard to sustainability, i.e., the requirements for sustainability governance. With a certain degree of simplification and without any claim of completeness, we identified five conceptual shifts and related governance requirements in the discourse around the 2030 Agenda. They refer to the construction of normativity, the substantive extension of the sustainability idea, the understanding of policy integration, the involvement of actors, and the sustainability idea's basic action orientation (see Table 1).

\subsection{Normativity}

Sustainability always has been attributed to a strong normative quality based on universal value-theoretical foundations (Dobson, 1996). Sustainability stands for a concept of human development that combines a complex idea of intergenerational and international justice with respect to ecological limits and the integrity of social-ecological systems (Christen \& Schmidt, 2012). For a long time, this understanding served as an open frame of reference for an increasingly evolving variety of sector- and context-specific concepts, rules, and criteria for sustainable development. Accordingly, the first task of sustainability-oriented governance was to clarify the meaning of sustainable development for the respective social, ecological, and economic contexts (Meadowcroft, 2007). The 2030 Agenda re-emphasizes sustainability's normativity while slightly altering its quality. Instead of an open normativity circulating around a generic sustainability definition, the Agenda promotes a system of 17 SDGs, each of which is specified further in terms of a set of targets and quantifiable indicators. For the first time in history, a relatively concrete system of goals exists specifying the direction of a societal transformation toward sustainability. These goals and their related targets now have become central reference points for thinking about and shaping sustainability governance, as well as key motivators for sustainability-oriented governance through global goals (Biermann et al., 2017; Kanie \& Biermann, 2017). As a consequence, new require- 
Table 1. Conceptual shifts in sustainability thinking and governance.

\begin{tabular}{lll}
\hline Conceptual element & Early generation of sustainability thinking & New generation of sustainability thinking \\
\hline Normativity & Universal but open definition & Differentiated global goal system \\
Extension & Ecological focus & Broad societal scope \\
Integration & Environmental policy integration & Systemic policy integration \\
Inclusion & Stakeholder participation & Engagement of 'the people' \\
Orientation & Social-ecological problems & Social-ecological transformation \\
\hline
\end{tabular}

ments for dealing with normativity have arisen, namely the need to translate global goals into local contexts and, inversely, to relate policy activities with overall global goals. This is reflected in a system of regular reporting by national governments to the UN-based High-Level Political Forum (Persson, Weitz, \& Nilsson, 2016).

This mechanism of normative translation, from global to local and back, leads to a partial closure of the interpretation horizon, i.e., any locally articulated understanding of sustainable development is now expected to connect to one or more global SDGs, if not to the SDG system as a whole. Therefore, sustainability governance practices must justify themselves in relation to SDGs. They also must be able to replace open interpretations of sustainability with localized interpretations of SDGs, which are integrated into a global monitoring and review system.

\subsection{Extension}

Sustainable development already had been framed in the Brundtland Report as a comprehensive sociopolitical idea comprising multiple goals linked to all kinds of action areas, including food security, protection of natural resources, energy, and urban development (Meadowcroft, 2000; WCED, 1987). Conceptual sustainability models covering multiple (usually ecological, economic, and social) dimensions, columns, or subsystems capture the idea's broad, descriptive, and normative scope (Purvis, Mao, \& Robinson, 2019). Although this extensive vision of sustainable development was reinvigorated in the international discourse, it has not always been embraced in academic and political discourse. In fact, there were strong tendencies to feature narrower sustainability conceptions, e.g., interpretations with an emphasis on the ecological dimension (Boström, 2012; Dobson, 1996). By linking the sustainability debate with the global development agenda, which so far has been epitomized by the Millennium Development Goals, the 2030 Agenda brings the sustainability idea's comprehensive character back to the fore and pushes it up to a new level (Langford, 2016; Le Blanc, 2015). The newly accentuated extension of sustainability is reflected inter alia in the Agenda's commitment to the Five P's-people, planet, prosperity, peace, and partnership-and its comprehensive goal architecture. Therefore, the 2030 Agenda is (finally) taking sustainabil- ity out of its ecological niche and elevating it to a model for society as a whole. Its implementation requires governance institutions and practices with the capacity to bring SDGs to bear the full spectrum of policy areas (Meuleman, 2019).

\subsection{Integration}

Sustainable development represents a political idea of social development that emphasizes the global character, inter-temporalism, and interdependence of crisis phenomena in the modern age (Meadowcroft, 2000). It problematizes the dominant model of societal development, which is characterized by a neglect of the interdependencies between the partial developments in different social subsystems and a disregard for their respective side effects and limits (Brand, 2017). To recognize interdependencies and address side effects, calls for (policy) integration have been stable elements of the sustainability debate (Bornemann, 2014). Sustainability governance essentially has been conceived as integrative governance, i.e., a form of governance that cuts across problem areas and policy silos. For a long time, an interpretation of integration in terms of environmental policy integration was dominant. This approach was aimed at infusing ecological goals into other policy areas (Jordan \& Lenschow, 2010) and sometimes prioritizing ecological concerns over other sectoral policy goals (Lafferty \& Hovden, 2003). This arguably has changed in the context of the 2030 Agenda. Starting from the notion of an indivisible goal system (Le Blanc, 2015; Nilsson \& Weitz, 2019), the focus is no longer on the unidirectional integration of sectoral goals into other policy areas. Integration instead refers to the analysis of mutual interactions in the form of trade-offs and synergies between basically all SDGs with the aim of identifying particularly 'critical' SDGs whose pursuance induces positive effects in the SDG system as a whole (Weitz, Carlsen, Nilsson, \& Skånberg, 2018; see also Bornemann \& Weiland, 2021; for a critical perspective on goal prioritization, see Forestier \& Kim, 2020). In terms of governance, this newly accentuated concept of integration requires SGAs that systematically can take into account the interrelationships between all SDGs that are relevant and meaningful in a given governance context, and on this basis, define priority SDGs (or targets) with the highest systemic impact. 


\subsection{Inclusion}

In the discussion about sustainable development and how to govern it, an insight quickly took hold that governments alone do not hold the responsibility and capacity to realize sustainable development. Instead, sustainability governance should include societal actors who not only become involved in defining what sustainable development means in particular contexts but also participate in sustainability-oriented problem-solving (Meadowcroft, 2007). It was, above all, Agenda 21 that emphasized participation as a central principle of sustainability governance (UNCED, 1992). It was argued that sustainable development cannot be decreed but that it must be initiated in a participatory manner involving relevant social actors, primarily organized stakeholders (Meadowcroft, 2004). With the turn toward the 2030 Agenda, we observed a slight shift in the interpretation of participation. While negotiators in certain countries were reluctant to include references to democracy, they still agreed on an understanding of participation that seemed to go beyond the established notion of stakeholder participation characteristic of the post-Rio sustainability debate (Langford, 2016). Both the process of formulating the 2030 Agenda, with its attempts to consult individual world citizens (Kamau, Chasek, \& O'Connor, 2018), and the emphatic reference to the 'people' in the preamble suggest that the stakeholder participation model is opening up to the broader civil society, including all kinds of organized and nonorganized collective and individual actors (Fukuda-Parr, 2016). This poses new challenges and requirements with regard to broad involvement by social actors in sustainability governance.

\subsection{Orientation}

Sustainable development is an idea that echoes the problematic consequences of the prevailing model of social development deeply rooted in the ideas, culture, and structures of (Western) modernity. In the context of the earlier sustainability discourse, these consequences were understood and addressed in terms of socialecological problems. Regarded as particularly complex or even 'wicked,' these problems generally are viewed as the objects of concern in sustainability governance (Voss, Newig, Kastens, Monstadt, \& Nölting, 2007). Although social-ecological problems continue to be an important reference point in sustainability thinking, the 2030 Agenda entails a broadening of the problem orientation toward shaping social-ecological transformations. The 2030 Agenda's vanishing point includes global goals that guide the transformation of our world (UN, 2015). Apart from emphasizing all countries' responsibility to take action in their respective contexts, the transformative turn that the 2030 Agenda promotes reflects the insight that simple adjustments within the existing system in the sense of problem-oriented solutions are insufficient to overcome the multiple social-ecological crises (Brand, 2017). Instead, the pervasive and open-ended character of the challenges for far-reaching, cross-sectoral, and cross-level changes to the system itself: A fundamental restructuring of economic production and consumption patterns and a reorientation of the individual and collective values and ways of thinking that produce them (Sachs et al., 2019). Therefore, sustainability governance in the sense of the 2030 Agenda primarily aims to shape social-ecological transformations (and less so to solve problems), placing specific requirements on SGAs' ability to take social-ecological change into account and make it the subject of governance processes.

\section{New Meets Old: Possibilities and Limitations of Sustainability Governance Arrangements in Implementing the 2030 Agenda}

We now turn to the question to what extent existing SGAs from the pre-2030 Agenda era are prepared to meet the 2030 Agenda's new governance requirements. To do so, we systematically relate the four ideal types of SGAs outlined in Section 2 with the five governance requirements presented in the previous Section 3 . This opens a structured interpretive space to evaluate the possibilities and limitations of SGAs to meet the 2030 Agenda's governance requirements (see Table 2).

\subsection{Problem-Oriented Sustainability Governance and the 2030 Agenda}

In problem-oriented SGAs, sustainability governance follows an incremental, piecemeal approach that addresses context-specific problems often associated with specific policy sectors. Problem-oriented SGAs seem well-suited to address the 2030 Agenda's normativity. For example, they lack collectively binding understandings of sustainability that could stand in the way of the SDGs as a new normative frame of reference. If the sustainability units succeed in refocusing their advisory resources on the SDGs, they can support the 'localization' of global goals by linking them to concrete problems on the ground. Moreover, considering that the responsible sustainability units are located within specialist administrative departments, they may have the expertise to monitor and compile information on the achievement of SDGs and relate that information to an overall global monitoring and review system.

However, for the same administrative specialization reason, problem-oriented SGAs tend to have a relatively narrow focus on only a few SDGs, thereby limiting their potential to address the extensive 2030 Agenda. Considering the sectoral anchoring of the sustainability unit and the prevailing logic of a sectoral approach to problems, the working agenda in such SGAs is determined less by overarching goals than by specific contextual problems. Problem-oriented SGAs certainly may try to refer to a wide range of SDGs in their problem- 
oriented sustainability advice, but they are neither in a structural position nor do they have the resources to initiate an extensive approach to implementing the SDG system as a whole. They also lack the power resources to push other administrative units to consider a broader range of SDGs beyond their usual problem framings.

Clear limits also exist for the problem-oriented type regarding the realization of the systemic integration model associated with the 2030 Agenda. Problem-oriented SGAs are more likely to follow the classical pattern of sectoral policymaking than to overcome it. It is quite possible that the 2030 Agenda could encourage actors to identify new links between sectoral problems and create new integrative settings in which previously unconnected issues are treated as nexus problems (see, for empirical indications, Tosun \& Leininger, 2017). However, given the limited resources of problem-oriented sustainability divisions, their sectoral orientation, and their distance from the decision-making center, it is rather unlikely that such an arrangement would be able to realize systemic policy integration, i.e., the analysis of contextrelated SDG interactions to identify priority goals for the government as a whole.

The ability to fulfill the 2030 Agenda's inclusion requirement is also likely to be rather weak in the context of a problem-oriented SGA. The anchoring of the responsible sustainability unit in a specialized department promotes a rational bureaucratic action logic that is rather exclusivist in social terms. Apart from organized stakeholders who voice their concerns through institutionalized channels of administrative interest mediation, there are no venues for broader participation of

Table 2. Assessment of the potentials of different SGA types to meet the 2030 Agenda's governance requirements.

\begin{tabular}{|c|c|c|c|c|}
\hline & $\begin{array}{l}\text { Problem-oriented } \\
\text { SGA }\end{array}$ & $\begin{array}{l}\text { Management-oriented } \\
\text { SGA }\end{array}$ & $\begin{array}{l}\text { Strategy-oriented } \\
\text { SGA }\end{array}$ & $\begin{array}{l}\text { Network-oriented } \\
\text { SGA }\end{array}$ \\
\hline $\begin{array}{l}\text { Normativity } \\
\text { Differentiated } \\
\text { global goal } \\
\text { system }\end{array}$ & $\begin{array}{l}+ \\
\text { Problem-related } \\
\text { reception and } \\
\text { reporting of selected } \\
\text { SDGs }\end{array}$ & $\begin{array}{l}+/- \\
\text { Established target } \\
\text { system and } \\
\text { monitoring practice, } \\
\text { but significant path } \\
\text { dependencies and } \\
\text { gridlock }\end{array}$ & $\begin{array}{l}+ \\
\text { Politically and legally } \\
\text { backed goal system }\end{array}$ & $\begin{array}{l}+/- \\
\text { Has potential to } \\
\text { connect goals to } \\
\text { activities of involved } \\
\text { societal actors, but } \\
\text { lacks systematic } \\
\text { monitoring and } \\
\text { reviewing }\end{array}$ \\
\hline $\begin{array}{l}\text { Extension } \\
\text { Broad societal } \\
\text { scope }\end{array}$ & $\begin{array}{l}- \\
\text { Focus on SDGs } \\
\text { relevant to } \\
\text { context-specific } \\
\text { problems only }\end{array}$ & $\begin{array}{l}+ \\
\text { Management system } \\
\text { prepared to cover } \\
\text { many policy areas }\end{array}$ & $\begin{array}{l}+/- \\
\text { Systemic extension, } \\
\text { but potentially limited } \\
\text { by political } \\
\text { considerations }\end{array}$ & $\begin{array}{l}+/- \\
\text { Dependent on } \\
\text { network extension, } \\
\text { but incentivized for } \\
\text { network expansion }\end{array}$ \\
\hline $\begin{array}{l}\text { Integration } \\
\text { Systemic policy } \\
\text { integration }\end{array}$ & $\begin{array}{l}+/- \\
\text { Punctual nexus } \\
\text { approaches, but no } \\
\text { systemic integration }\end{array}$ & $\begin{array}{l}+/- \\
\text { Capacity to analyze } \\
\text { systemic interactions, } \\
\text { but not for setting } \\
\text { priorities }\end{array}$ & $\begin{array}{l}+ \\
\text { Has potential to } \\
\text { analyze interactions } \\
\text { and to identify and } \\
\text { propose policy } \\
\text { priorities }\end{array}$ & $\begin{array}{l}- \\
\text { Accidental setup of } \\
\text { nexus problems, but } \\
\text { no systemic } \\
\text { integration and } \\
\text { identification of policy } \\
\text { priorities }\end{array}$ \\
\hline $\begin{array}{l}\text { Inclusion } \\
\text { Broad } \\
\text { engagement of } \\
\text { 'the people' }\end{array}$ & $\begin{array}{l}-/+ \\
\text { No established } \\
\text { participation practice, } \\
\text { but has potential for } \\
\text { problem-oriented } \\
\text { inclusion of different } \\
\text { actors }\end{array}$ & $\begin{array}{l}\text { No consideration of } \\
\text { external actors due to } \\
\text { inward-looking } \\
\text { efficiency-oriented } \\
\text { management logic }\end{array}$ & $\begin{array}{l}\text { Exclusivist logic; } \\
\text { actors included only if } \\
\text { politically promising }\end{array}$ & $\begin{array}{l}+ \\
\text { Experience in } \\
\text { organizing } \\
\text { stakeholder } \\
\text { participation, but less } \\
\text { so in citizen } \\
\text { participation }\end{array}$ \\
\hline $\begin{array}{l}\text { Orientation } \\
\text { Social-ecological } \\
\text { transformation }\end{array}$ & $\begin{array}{l}\text { Focus on solving } \\
\text { problems rather than } \\
\text { shaping } \\
\text { transformations }\end{array}$ & $\begin{array}{l}\text { - } \\
\text { Efficiency logic } \\
\text { encourages process } \\
\text { optimization, rather } \\
\text { than substantial } \\
\text { transformation }\end{array}$ & $\begin{array}{l}+ \\
\text { Has potential to } \\
\text { connect the } 2030 \\
\text { Agenda to } \\
\text { transformative } \\
\text { political agendas }\end{array}$ & $\begin{array}{l}+/- \\
\text { Has capacity to } \\
\text { mobilize actors from } \\
\text { below, but } \\
\text { disconnected from } \\
\text { political agenda }\end{array}$ \\
\hline
\end{tabular}


all kinds of organized and non-organized societal actors. However, the problem-oriented governance type's orientation toward specific problems 'on the ground,' in principle, can provide a promising basis for cooperation with other social actors working on the localization of SDGs.

Another limitation of problem-oriented SGAs concerns the implementation of the 2030 Agenda's transformative orientation. The practical focus of this type of arrangement is on identifying and solving confined problems, whereas the 2030 Agenda calls for engaging with societal transformations. It is obvious that all attempts to solve sustainability problems most likely impact transformations. However, problem-oriented SGAs do not seem to have the capacity to consider the fundamental embedding of problems in social change processes and make these processes the objects of governance.

\subsection{Management-Oriented Sustainability Governance and the 2030 Agenda}

Management-oriented SGAs generally are well-prepared to embrace the 2030 Agenda's new normative quality. Because they are based on a goal-oriented management cycle that includes the continuous monitoring and evaluation of progress toward specific sustainability goals, they fit well into the global monitoring and review process organized by the High-Level Political Forum. While a management rationale seems to be congruent with the management process that the 2030 Agenda implies, impeding factors also exist. The investments that have been made to build and maintain the existing sustainability-oriented goal and monitoring system create certain path dependencies that could be the basis for a potential aversion to change. The challenge is to transform existing goal and indicator systems, which have been developed and maintained for years, into new systems aligned with the SDGs and, thus, a political challenge that is certainly beyond the capacity of a management approach. Given rather scarce political support and administrative resources, it is questionable whether management-oriented SGAs can overcome path dependencies and replace existing goal and indicator systems with new ones.

In contrast to the problem-oriented type of SGA's rather selective and narrow scope, which is limited to only those SDGs that are related to concrete problems on the ground, a management-oriented governance style offers prima facie supportive conditions for extensive coverage of the SDG system. With management-oriented SGAs, sustainability units occupy a comparatively high position in the administrative hierarchy, allowing them to oversee the activities of the entire government apparatus. In combination with a comprehensive management process that basically covers the government's entire policy universe, this enables these units to monitor the sustainability implications of all possible policy areas.

Management-oriented SGAs' efficiency orientation can be conducive to responding to the 2030 Agenda's new integration requirements. Integration, in the context of the Agenda, is about understanding the systemic interactions between SDGs to identify these goals, whose pursuit with the lowest possible use of resources leads to the greatest possible effects in the SDG system. The management-oriented type of SGA provides a suitable framework for such efficiency-oriented goal definition. The prioritization logic of the 2030 Agenda, which is geared toward pursuing the most impactful goals possible, corresponds with a management approach geared toward realizing efficiency gains.

Management-oriented SGAs focus on step-by-step achievement of objectives and the continuous improvement of relevant processes, including management cycles. The focus is clearly on internal governance processes, for which more extensive and differentiated information is made available with the help of monitoring and evaluation systems. External societal actors' involvement plays a rather subordinate role in such an inward-looking, efficiency-oriented management rationale. Given its relative exclusivity, the management-oriented governance approach is hardly prepared to enable broader inclusion of non-organized stakeholders and citizens. Inclusion only plays a role when it serves to optimize the management process, e.g., by enabling more efficient knowledge generation with the help of societal and civil society actors.

With their goal and monitoring systems, management-oriented SGAs seem well-prepared to adopt the 2030 Agenda's transformative orientation. These systems are geared toward continuously observing societal dynamics and providing the knowledge basis for considering these dynamics in policymaking and governance. However, two potential drawbacks exist. One is that the efficiency logic prevailing in managementoriented SGAs can lead to an attempt to adapt the existing goal systems as smoothly and as conflict-free as possible to the SDGs, instead of changing them substantially in the direction of the SDGs. Another potential drawback is that management-oriented SGAs generally focus on monitoring aggregate social developments, not policy outputs and impacts as such, which would provide an important basis for transformative governance.

\subsection{Strategy-Oriented Sustainability Governance and the 2030 Agenda}

Strategy-oriented sustainability governance is about creating, shaping, and using political opportunities to foster the integration of sustainability into government action. Such an approach should be well-equipped to adopt the 2030 Agenda's new normative quality, i.e., to translate the 2030 Agenda into localized understandings of sustainability that are connected to the global goals. Considering that strategy-oriented arrangements already contain overarching sustainability goalssometimes even linked to constitutional principles, overarching government visions, and long-term government 
strategies-the SDGs encounter a differentiated, legally, and politically backed system of sustainability principles and goals. While this tends not to be the case for the management-oriented approach, strategy-oriented SGAs are more political and more easily can link the SDGs to politically relevant goals and agendas. Consequently, there is a greater chance than in management-oriented SGAs that the transition to a new goal system based on the SDGs will receive political attention and support and that SDGs' implementation will be embedded in relevant political agendas.

The political logic of strategy-oriented SGAs, however, is a potential drawback for considering the broad extension of the 2030 Agenda because it promotes selective interpretation and adoption of sustainable development goals (see Forestier \& Kim, 2020). Thus, strategy-oriented sustainability divisions are encouraged to focus only on those parts of the goal system that are most promising in terms of political impact. SDGs that lie outside the spectrum of political attention, e.g., because they are viewed as irrelevant to the profiling of political decision-makers vis-à-vis voters, may be neglected. However, the close connection between sustainability and overarching governmental goal and planning schemes, characteristic of strategically oriented SGAs, provides fertile ground for the 2030 Agenda to become a meta-policy that guides several first-order policies in all areas of government action (Meuleman \& Niestroy, 2015).

The relatively high anchoring of the strategyoriented SGA provides a promising context for dealing with the 2030 Agenda's new integration requirement. Departments will be urged to work together if clear political commitments and expectations must be fulfilled. Whereas an arrangement at the working level always will encounter systematic boundaries to push for integration, a politically backed strategic arrangement may not be in a position to enforce integration, but it can activate respective support to encourage departments to work together. However, there is also a drawback. Integration in the context of the 2030 Agenda involves the systematic analysis of contextual goal interactions and, based on this, a prioritization of those goals that promise the greatest overall benefits. When the analytically derived priorities are not consistent with political goals, the latter will overshadow the former.

Similarly, the demand for inclusion is likely to be met only sporadically whenever social actors' participation in the respective strategy-oriented SGA is viewed as politically favorable. This concern underscores general doubts about the strategy-oriented governance type's inclusivity. Given its placement high in the administrative hierarchy and near the political decision center, there might be a tendency in this arrangement to adopt an elitist orientation that is disconnected from stakeholders and citizens' concerns. The inclusion of these actors might be pursued only as far as it is deemed politically useful, thereby leading to a selective interpretation and practice of actor participation.
Similar to management-oriented SGAs, strategyoriented approaches to sustainability governance typically include capacities for monitoring societal dynamics and reflecting on them in light of SDGs. In addition, strategy-oriented SGAs also provide approaches to policy monitoring, which enable policy learning. Given their proximity to the political decision center, they also have considerable capacities to establish links between SDGs and relevant political agendas and policy processes. Taken together, this elicits a considerable potential to address the 2030 Agenda's transformative orientation.

\subsection{Network-Oriented Sustainability Governance and the 2030 Agenda}

In a network-oriented SGA, sustainability governance is about creating and maintaining links between administrative and social actors. The network serves as a basis for launching concrete sustainability projects and mobilizing societal support that drives government action toward sustainability. On the one hand, networkoriented SGAs have a considerable potential to embrace the 2030 Agenda's normative requirements. The intensive communicative exchange between administrative and social actors offers a solid basis for developing links between the Agenda and context-relevant sustainability issues in terms of locally meaningful interpretations of SDGs. Due to their project-oriented focus, which is, at best, loosely related to an overarching sustainability vision, network-oriented SGAs do not face the challenge of overcoming or adapting existing goal and indicator systems. Instead, they enter an untapped field and have much conceptual leeway for making sense of the SDGs on the ground. On the other hand, the lack of systematic approaches and experience in dealing with overarching sustainability goals impairs their ability to collect and monitor the contributions of local sustainability projects and report them to a national or global monitoring and review system.

Network-oriented SGAs' potential to meet the 2030 Agenda's extension requirements is equally ambivalent. The extent to which it can take over the entire spectrum of SDGs, or only a selection of some SDGs, will depend on the already existing network's size and composition. The rather open bottom-up approach to identifying and pursuing sustainability-related issues relevant to local social actors carries the risk that only a few SDGs will be viewed as meaningful and relevant, while other SDGs that are not represented by network actors will fall through the cracks. However, given that network-based SGAs are incentivized to grow in size (to maintain or expand their government-provided resource base), the sustainability units that usually organize the network could view the 2030 Agenda as a strategic moment to address new issues and reach out to actors that were previously outside the scope of sustainability governance.

Regarding integration, network-oriented SGAs' potential is also ambivalent. On the one hand, the posi- 
tioning of the sustainability unit outside the administration, its relative autonomy from sectoral constraints, and the diversity of the social actors involved in the network offer favorable conditions for interlocking multiple sectoral problems and SDGs into integrative nexus arrangements. On the other hand, network-oriented SGAs lack the potential to follow the systemic integration approach that the 2030 Agenda advocates, which entails systematically analyzing interactions between SDGs to identify priority goals whose pursuit would create positive ripple effects for the SDG system as a whole. Not only do the respective arrangements lack the resources and expertise to conduct systematic and contextualized analyses of SDG interactions, but they also have no mandate and no political support to identify and communicate political priorities to be pursued by the government as a whole.

For quite obvious reasons, network-oriented arrangements appear to be relatively well-prepared to implement the 2030 Agenda's inclusion requirements. Because of their characteristic outward orientation toward society, these arrangements are most likely to have experience with involving interest groups in shaping sustainable development. Considering that incentives exist to expand the network to maintain their resource base, the organizers of the sustainability governance network could use the Agenda as an opportunity to reach out to new actors and involve them in governance arrangements. Given the predominant focus on organized stakeholders, one challenge for networkoriented SGAs could be to involve non-organized individual actors, such as citizens or residents. These actors have preferences and interaction orientations that differ from organized stakeholder groups, as well as different expectations in terms of the organization of participation processes.

Network-oriented SGAs' relative distance from the political decision-making center is also a condition for their mixed transformation potential. On the one hand, they have considerable potential to initiate and drive transformations from below, e.g., by bringing social actors together and mobilizing them to address nexus problems. This is also likely to stimulate transformation in the government and administration. On the other hand, their transformative potential is highly selective and localized, and not systematically tied to the monitoring of overarching social-ecological dynamics in the respective context. They also remain potentially detached from overarching governmental processes that are designed to monitor and shape social-ecological dynamics.

Overall, the analysis shows that the four idealtypical SGAs have different potentials to realize the 2030 Agenda's governance requirements. In some instances, contingent potentials are discernible. None of the ideal-typical arrangements fulfills all requirements, but in looking across the requirements, it appears that they all can be met by different SGAs. Accordingly, while there appears to be no single SGA that is fully prepared to implement the 2030 Agenda, different arrangements are prepared to meet specific requirements. For a complete fulfillment of all requirements, the virtues of different ideal types would need to be combined in hybrid SGAs. For example, strategy-oriented approaches could overcome their potential weaknesses in terms of inclusion by adopting participatory elements characteristic of network-oriented arrangements.

\section{Conclusion and Perspectives}

To what extent are governments equipped to implement the more recent 2030 Agenda within their existing arrangements of sustainability governance that date from an earlier period? This article argues that the 2030 Agenda does not mean a simple continuation of 'business as usual' in governing sustainability. Instead, governments face a generational shift in sustainability thinking that brings with it new governance requirements and challenges the governance arrangements already in place.

The 2030 Agenda is characterized by a specific normativity and a broad substantive extension of the scope of sustainable development, a systemic policy integration concept, a highly inclusive outlook, and a transformative action orientation. In their implementation, these requirements encounter established governance arrangements that are intended to turn sustainability into government action. Using four ideal-typical SGAs that stem from an analysis of Swiss cantons as an example, we have shown how the five specific governance requirements match or challenge these four ideal-typical arrangements and their respective governance rationales. Although our analysis is merely illustrative, and we make no particular generalization claims, we assume that the four governance rationales can be found in SGAs outside Swiss cantons (Bornemann \& Christen, 2019a), which is why our observations are also relevant to other contexts.

Our analysis suggests that none of the four idealtypical SGAs meets all five requirements. The arrangements come with different possibilities and limitations with respect to meeting the governance requirements associated with the conceptual shifts in sustainability thinking emerging in the wake of the 2030 Agenda. Further in-depth qualitative case studies should show whether there are real existing SGAs that succeed in meeting all requirements by combining different elements of the four ideal-typical arrangements. Such analyses also would need to consider whether and to what extent actual measures to implement the 2030 Agenda influence or even change existing SGAs' functioning.

From a practical perspective, we conclude that implementing the 2030 Agenda requires a close examination of existing SGAs' functioning in relation to the Agenda's new governance requirements. Such an examination could reveal the need for targeted and contextdependent adjustments of existing governance arrangements, making 2030 Agenda implementation not only a 
question of organizing and steering societal transformations but also of transforming existing SGAs. The discussion of the possibilities and limitations of ideal-typical SGAs in dealing with the five governance requirements indicates where such sustainability governance transformations should begin and what they should target. It thereby opens up perspectives on how to design real-world governance arrangements that combine the respective strengths of different ideal-typical SGAs to meet the governance requirements that arise in the wake of the new generation of sustainability thinking under the 2030 Agenda.

\section{Acknowledgments}

We thank the three anonymous reviewers and the Academic Editors for their constructive comments, which helped us improve the article significantly. The research presented is part of the 'The Sustainabilization of the State' project, which is supported by the Swiss National Science Foundation under Grant No. 178810.

\section{Conflict of Interests}

The authors declare no conflicts of interest.

\section{References}

Allen, C., Metternicht, G., \& Wiedmann, T. (2018). Initial progress in implementing the Sustainable Development Goals (SDGs): A review of evidence from countries. Sustainability Science, 13(5), 1453-1467. https://doi.org/10.1007/s11625-018-0572-3

Baker, S., \& Eckerberg, K. (Eds.). (2008). In pursuit of sustainable development: New governance practices at the sub-national level in Europe. London: Routledge.

Biermann, F., Kanie, N., \& Kim, R. E. (2017). Global governance by goal-setting: The novel approach of the UN Sustainable Development Goals. Current Opinion in Environmental Sustainability, 26/27, 26-31. https:// doi.org/10.1016/j.cosust.2017.01.010

Biermann, F., \& Lövbrand, E. (Eds.). (2019). Anthropocene encounters: New directions in green political thinking. Cambridge: Cambridge University Press.

Boas, I., Biermann, F., \& Kanie, N. (2016). Crosssectoral strategies in global sustainability governance: Towards a nexus approach. International Environmental Agreements: Politics, Law and Economics, 16(3), 449-464. https://doi.org/10.1007/ s10784-016-9321-1

Börjeson, L., Höjer, M., Dreborg, K.-H., Ekvall, T., \& Finnveden, G. (2006). Scenario types and techniques: Towards a user's guide. Futures, 38(7), 723-739. https://doi.org/10.1016/j.futures.2005.12.002

Bornemann, B. (2014). Policy-Integration und Nachhaltigkeit: Integrative Politik in der Nachhaltigkeitsstrategie der deutschen Bundesregierung [Policy integration and sustainability: Integrative policymaking in the sustainability strategy of the German Federal Government] (2nd ed.). Wiesbaden: Springer VS.

Bornemann, B., \& Christen, M. (2019a). Sustainability governance in public administration: Interpreting practical governance arrangements in Swiss cantons. Environmental Policy and Governance, 29(3), 159-169. https://doi.org/10.1002/eet.1840

Bornemann, B., \& Christen, M. (2019b). Sustainabilizing the government machinery? Exploring sustainabilityoriented transformations of internal governance in Swiss cantons. In P. Hamman (Ed.), Sustainability governance and hierarchy (pp. 115-135). London: Routledge.

Bornemann, B., \& Weiland, S. (2021). The UN 2030 Agen$\mathrm{da}$ and the quest for policy integration: A literature review. Politics and Governance, 9(1), 96-107. https://doi.org/10.17645/pag.v9i1.3654

Boström, M. (2012). A missing pillar? Challenges in theorizing and practicing social sustainability: Introduction to the special issue. Sustainability: Science, Practice and Policy, 8(1), 3-14. https://doi.org/10.1080/ 15487733.2012.11908080

Bowen, K. J., Cradock-Henry, N. A., Koch, F., Patterson, J., Häyhä, T., Vogt, J., \& Barbi, F. (2017). Implementing the "Sustainable Development Goals": Towards addressing three key governance challenges: Collective action, trade-offs, and accountability. Current Opinion in Environmental Sustainability, 26/27, 90-96. https://doi.org/10.1016/j.cosust. 2017.05.002

Brand, K.-W. (Ed.). (2017). Die sozial-ökologische Transformation der Welt: Ein Handbuch [The socialecological transformation of the world: A handbook]. Frankfurt: Campus.

Bruyninckx, H., Happaerts, S., \& Van den Brande, K. (Eds.). (2012). Sustainable development and subnational governments: Policymaking and multi-level interactions. Houndmills and Basingstoke: Palgrave Macmillan.

Christen, M., \& Schmidt, S. (2012). A formal framework for conceptions of sustainability: A theoretical contribution to the discourse in sustainable development. Sustainable Development, 20(6), 400-410. https:// doi.org/10.1002/sd.518

Christensen, T., \& Lægreid, P. (2006). New public management: The transformation of ideas and practice. Aldershot: Ashgate.

Dobson, A. (1996). Environment sustainabilities: An analysis and a typology. Environmental Politics, 5(3), 401-428. https://doi.org/10.1080/09644019 608414280

Forestier, O., \& Kim, R. E. (2020). Cherry-picking the Sustainable Development Goals: Goal prioritization by national governments and implications for global governance. Sustainable Development, 28(5), 1269-1278. https://doi.org/10.1002/sd.2082

Fukuda-Parr, S. (2016). From the Millennium Devel- 
opment Goals to the Sustainable Development Goals: Shifts in purpose, concept, and politics of global goal setting for development. Gender \& Development, 24(1), 43-52. https://doi.org/ 10.1080/13552074.2016.1145895

Grunwald, A. (2007). Working towards sustainable development in the face of uncertainty and incomplete knowledge. Journal of Environmental Policy \& Planning, 9(3/4), 245-262. https://doi.org/10.1080/ 15239080701622774

Hajer, M., Nilsson, M., Raworth, K., Bakker, P., Berkhout, F., de Boer, Y., ... Kok, M. (2015). Beyond cockpit-ism: Four insights to enhance the transformative potential of the Sustainable Development Goals. Sustainability, 7(2), 1651-1660. https://doi.org/10.3390/ su7021651

Hansen, K. M., \& Ejersbo, N. (2002). The relationship between politicians and administrators: A logic of disharmony. Public Administration, 80(4), 733-750. https://doi.org/10.1111/1467-9299.00326/abs

Jahn, T., Bergmann, M., \& Keil, F. (2012). Transdisciplinarity: Between mainstreaming and marginalization. Ecological Economics, 79, 1-10. https://doi.org/ 10.1016/j.ecolecon.2012.04.017

Jordan, A., \& Lenschow, A. (2010). Environmental policy integration: A state of the art review. Environmental Policy and Governance, 20(3), 147-158. https:// doi.org/10.1002/eet.539

Kamau, M., Chasek, P. S., \& O'Connor, D. C. (2018). Transforming multilateral diplomacy: The inside story of the Sustainable Development Goals. London and New York, NY: Routledge.

Kanie, N., \& Biermann, F. (Eds.). (2017). Earth system governance: Governing through goals: Sustainable Development Goals as governance innovation. Cumberland: MIT Press.

Koppenjan, J., \& Klijn, E.-H. (2004). Managing uncertainties in networks: A network approach to problem solving and decision making. London and New York, NY: Routledge.

Lafferty, W. M., \& Hovden, E. (2003). Environmental policy integration: Towards an analytical framework. Environmental Politics, 12(3), 1-22.

Lafferty, W. M., \& Meadowcroft, J. (Eds.). (2000). Implementing sustainable development: Strategies and initiatives in high consumption societies. Oxford: Oxford University Press.

Langford, M. (2016). Lost in transformation? The politics of the sustainable development goals. Ethics \& International Affairs, 30(2), 167-176. https://doi.org/ $10.1017 /$ S0892679416000058

Le Blanc, D. (2015). Towards Integration at last? The Sustainable Development Goals as a network of targets. Sustainable Development, 23(3), 176-187. https:// doi.org/10.1002/sd.1582

Meadowcroft, J. (2000). Sustainable development: A new(ish) idea for a new century? Political Studies, 48(2), 370-387. https://doi.org/10.1111/1467-9248. 00265/abs

Meadowcroft, J. (2004). Participation and sustainable development: Modes of citizen, community and organisational involvement. In W. M. Lafferty (Ed.), Governance for sustainable development: The challenge of adapting form to function (pp. 162-190). Cheltenham and Northampton, MA: Edward Elgar Publishing.

Meadowcroft, J. (2007). Who is in charge here? Governance for sustainable development in a complex world. Journal of Environmental Policy \& Planning, 9(3), 299-314. https://doi.org/10.1080/ 15239080701631544

Meadowcroft, J., Banister, D., Holden, E., Langhelle, O., Linnerud, K., \& Gilpin, G. (Eds.). (2019). What next for sustainable development? Our common future at thirty. Cheltenham and Northampton, MA: Edward Elgar Publishing.

Meuleman, L. (2019). Metagovernance for sustainability: A framework for implementing the Sustainable Development Goals. London and New York, NY: Routledge.

Meuleman, L., \& Niestroy, I. (2015). Common but differentiated governance: A metagovernance approach to make the SDGs work. Sustainability, 7(9), 12295-12321. https://doi.org/10.3390/su70912295

Newell, P., Taylor, O., Naess, L. O., Thompson, J., Mahmoud, H., Ndaki, P., . . . Teshome, A. (2019). Climate smart agriculture? Governing the Sustainable Development Goals in Sub-Saharan Africa. Frontiers in Sustainable Food Systems, 3. https://doi.org/10.3389/ fsufs.2019.00055

Nilsson, M., \& Weitz, N. (2019). Governing trade-offs and building coherence in policymaking for the 2030 Agenda. Politics and Governance, 7(4), 254-263. https://doi.org/10.17645/pag.v7i4.2229

OECD. (2007). Institutionalising sustainable development. Paris: OECD.

Paehlke, R., \& Torgerson, D. (Eds.). (1990). Managing Leviathan: Environmental politics and the administrative state. Lewiston, NY: Broadview Press.

Persson, Å., Weitz, N., \& Nilsson, M. (2016). Follow-up and review of the Sustainable Development Goals: Alignment vs. internalization. Review of European, Comparative \& International Environmental Law, 25(1), 59-68. https://doi.org/10.1111/reel.12150

Purvis, B., Mao, Y., \& Robinson, D. (2019). Three pillars of sustainability: In search of conceptual origins. Sustainability Science, 14(3), 681-695. https://doi.org/ 10.1007/s11625-018-0627-5

Sachs, J. D., Schmidt-Traub, G., Mazzucato, M., Messner, D., Nakicenovic, N., \& Rockström, J. (2019). Six transformations to achieve the sustainable Development Goals. Nature Sustainability, 2(9), 805-814. https:// doi.org/10.1038/s41893-019-0352-9

Stafford-Smith, M., Griggs, D., Gaffney, O., Ullah, F., Reyers, B., Kanie, N., . . . O'Connell, D. (2017). Integration: The key to implementing the Sustainable Development Goals. Sustainability Science, 12(6), 911-919. 
https://doi.org/10.1007/s11625-016-0383-3

Steurer, R. (2007). From government strategies to strategic public management: An exploratory outlook on the pursuit of cross-sectoral policy integration. European Environment, 17, 201-214.

Steurer, R. (2008). Sustainable development strategies. In A. Jordan \& A. Lenschow (Eds.), Innovation in environmental policy? Integrating the environment for sustainability (pp. 93-113). Cheltenham and Northampton, MA: Edward Elgar Publishing.

Steurer, R. (2010). Sustainable development as a governance reform agenda: Principles and challenges. In R. Steurer \& R. Trattnigg (Eds.), Nachhaltigkeit regieren: Eine Bilanz zu Governance-Prinzipien undPraktiken [Governing sustainability: A review of governance principles and practices] (pp. 33-52). Munich: Oekom Verlag.

Steurer, R., \& Hametner, M. (2013). Objectives and indicators in Sustainable Development Strategies: Similarities and variances across Europe. Sustainable Development, 21(4), 224-241. https://doi.org/ 10.1002/sd.501

Tils, R. (2007). The German sustainable development strategy: Facing policy, management and political strategy assessments. European Environment, 17, 164-176. https://doi.org/10.1002/eet.453

Tosun, J., \& Leininger, J. (2017). Governing the Interlinkages between the Sustainable Development Goals: Approaches to attain policy integration. Global Challenges, 1(9). https://doi.org/10.1002/gch2. 201700036

\section{About the Authors}

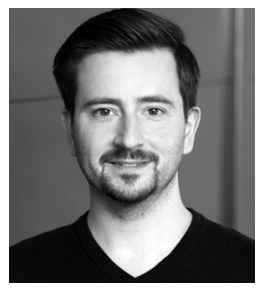

Basil Bornemann is a Postdoctoral Researcher and Lecturer at the Sustainability Research Group, University of Basel. He has an interdisciplinary study background in environmental sciences and holds a doctoral degree in political science. His research focusses on sustainability-oriented governance transformations and their democratic implications in various areas such as energy and food. At present, he is involved in a research project on the sustainabilisation of the state funded by the Swiss National Science Foundation (SNSF).

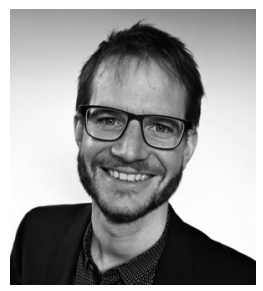

Marius Christen studied philosophy and history at the University of Basel and completed his doctorate with a thesis on the axiological fundament of sustainability. After gaining practical experience in a local Agenda 21, he returned as a Postdoctoral Researcher to the Sustainability Research Group at the University of Basel. His research focuses on the sustainabilization of the state. Additional to his academic studies, he consults public administration and is overall interested in connecting practical with scientific knowledge. 